\title{
Assessment of Prevalence and Risk Factors for Anemia Among Pregnant Mothers Attending Anc Clinic at Adama Hospital Medical Collage, Adama, Ethiopia, 2017
}

\author{
Bizuneh Ayano ${ }^{1}$, Befekadu Amentie ${ }^{2}$ \\ ${ }^{1}$ Department of Public health, Addis Ababa University, Selale Campus, Fiche, Ethiopia \\ ${ }^{2}$ Department of Medical Ward, Adama Hospital Medical College, Adamma, Ethiopia
}

Email address:

bizunehayano@gmail.com (B. Ayano)

\section{To cite this article:}

Bizuneh Ayano, Befekadu Amentie. Assessment of Prevalence and Risk Factors for Anemia Among Pregnant Mothers Attending Anc Clinic at Adama Hospital Medical Collage, Adama, Ethiopia, 2017. Journal of Gynecology and Obstetrics. Vol. 6, No. 3, 2018, pp. 31-39. doi: 10.11648/j.jgo.20180603.11

Received: November 2, 2017; Accepted: May 2, 2018; Published: May 24, 2018

\begin{abstract}
Background: Anemia is a significant public health problem in developing countries, particularly in pregnant women. It refers to a condition in which the hemoglobin content of the blood is lower than normal. In developing countries, the cause of anemia during pregnancy is multifactorial and includes nutritional deficiencies. It is associated with an increased risk of maternal and perinatal morbidity and mortality. In order to design an intervention for prevention of anemia in pregnancy, determination of its magnitude and identifying associated risk factors for anemia are paramount importance. Objectives: To determine the magnitude and factors associated with anemia during pregnancy among mothers attending antenatal care at Adama Hospital Medical College antenatal care clinic from November to December 2017. Methods: Institution based cross sectional study design was used in Adama Hospital Medical College from November to December 2017. The study participants were selected using systematic sampling technique from their sequence of antenatal care visit in the period of study, and associated risk factors data were collected using structured questionnaire by trained antenatal care service providers. Level of haemoglobin was determined. Descriptive and analytical statistics were computed using SPSS version 20. Odds Ratios, P-values and $95 \%$ CIs - the analytical statistics from bivariate and multi variate logstic regression were used to identify predictor variables associated with the dependent variable - anaemia. Result: A total of 329 participants completed the study making the response rate of $97.0 \%$. The mean age of the participants was $(26.5 \pm 4.03)$. The prevalence of anaemia was found to be $14.9 \%$. Pregnant women who had pica during pregnancy had 33.6(13.92 -81.48) times more likely to be anemic compared with those had no history of pica. Pregnant women who didn't take iron supplementation during their pregnancy were 0.196(.085-.445) times more likely to be affected by anemia when they compared with those who took iron supplementation. Conclusion: The prevalence of anaemia was found to be $14.9 \%$. Iron supplementation during pregnancy and presence of pica were significantly associated with anaemia in the study population. Therefore, long term and short term strategies helpful in alleviating these predisposing factors need to be developed so as to reduce the number of mothers affected by anaemia.
\end{abstract}

Keywords: Anaemia, Magnitude, Factors, Pregnancy, Ethiopia

\section{Introduction}

\subsection{Background}

Anemia is defined as a condition in which there is less than the normal hemoglobin $(\mathrm{Hb})$ level in the body, which decreases oxygen-carrying capacity of red blood cells to tissues. Anemia is a global public health problem affecting both developed and developing countries with major consequences for human health as well as social and economic development. It occurs at all stages of the life cycle $[1,2]$. 
Anemia is one of the most common nutritional deficiency diseases observed globally. Although nutritional anemia affects members of both sexes and all age groups, the problem is more prevalent among women and contributes to maternal morbidity and mortality, as well as to low birthweight [3]. It has been estimated that nutritional anemia affects almost two-thirds of pregnant women in developing countries. However, many of these women were already anemic at the time of conception, with an estimated prevalence of anemia of almost $50 \%$ among nonpregnant women in developing countries [4].

According to the 2008 World Health Organization (WHO) report, anaemia affected 1.62 billion $(24.8 \%)$ people globally [5]. It had an estimated global prevalence of $42 \%$ in pregnant women and is a major cause of maternal mortality [6-8]. In Africa, $57.1 \%$ of the pregnant women were anemic. Moreover, anemia in pregnant women is a severe public health problem in Ethiopia; $62.7 \%$ of pregnant women were anemic [5]. Although the prevalence varies widely in different settings and accurate data are often lacking, in resource-limited areas terribly significant proportions of women of childbearing age particularly pregnant are anaemic [9]. Geographically, those living in Asia and Africa are at the greatest risk [10].

Seventeen percent of Ethiopian women in the reproductive age group are anemic and $22 \%$ of these women were pregnant [11]. Anaemia may result from both nutritional and nonnutritional factors, specifically besides iron, deficiency of micronutrients such as vitamins A, C and B-12 and folic acid may contribute to the development of anaemia. These nutrients may affect haemoglobin synthesis either directly or indirectly by affecting absorption and/or mobilization [3].

Epidemiological studies done on prevalence of anemia in pregnant women in Ethiopia have reported varying magnitude of anemia and identified several factors associated with anemia [12-21]. Determination of the magnitude of anemia among pregnant women helps to monitor health of the pregnant women, contributing to reduction in maternal morbidity and mortality. Also, assessment of factors predisposing to anemia in a local area enables to take targeted intervention activities.

\subsection{Statement of the Problem}

The effect of anemia during pregnancy on maternal and neonatal life ranges from varying degrees of morbidity to mortality. As many studies elucidated, severe anemia $(<7 \mathrm{~g} / \mathrm{L})$ during pregnancy has been associated with major maternal and fetal complications. It increases the risk of preterm delivery [23, 24], low birth weight [22-24], intrauterine fetal death [24], neonatal death [25], maternal mortality [26], and infant mortality [27]. Anemia is multifactorial in etiology; the disease is thought to be mainly caused by iron deficiency in developing countries. In subSaharan Africa where iron deficiency is common, the prevalence of anemia has often been used as a proxy for iron deficiency anemia (IDA) [9]. Other micronutrient deficiency (vitamins A and B12, riboflavin, and folic acid) has also been a cause of anemia during pregnancy [28].

Likewise, Infectious diseases such as malaria, helminthes infestations, and HIV are also implicated with high prevalence of anemia in sub-Saharan Africa [29, 30]. There was also a considerable variation in the prevalence of pregnancy anemia because of the differences in socioeconomic conditions, lifestyles, and health seeking behaviors of different population across different countries and cultures and obstetrics and gynecological related condition of pregnant mothers [28].

Anaemia is especially dangerous in pregnant women in that it causes cardiac failure, hemorrhage and infection. In India, $19 \%$ of maternal deaths were related to anaemia. Maternal anaemia increases intrauterine growth retardation and pre-term delivery. Anaemia is also an important indicator for choosing medication. For example anaemic women should be strict to the use of intrauterine device due to blood loss side effect [31].

Anaemia has been shown to affect cognitive development, shorten attention span, and cause irritability, fatigue, difficulty with concentration, lethargy, increased mortality, and susceptibility to infection. Consequently, anemic children tend to perform poorly on vocabulary, reading and other tests. However, with appropriate preventive programs, many cases of anaemia, including iron deficiency anaemia, can be prevented in children [32].

Strong evidence links anemia not only to health problem but also development problem. Anemia increases risk for maternal and child mortality and has negative consequences on the cognitive and physical development of children, and also has negative impact on work productivity in adults which affect economical activity. Overall, about $20 \%$ of maternal and perinatal mortality in developing countries can be attributed to anemia. Iron deficiency with/without anemia reduces work productivity in adults and limits cognitive development in children, thus limiting their achievement in school and ultimately reducing investment benefits in education [33-35]

Studies conducted over the years witnessed the public health significance of anemia in Ethiopia. A study in 1999 by Haider et al (36) reported that $18.4 \%$ of pregnant and lactating women in rural Ethiopia were anaemic. In 2006, Micronutrient Initiative (MI) Ethiopia estimated $27.0 \%$ and $30.6 \%$ prevalence of anemia among women of reproductive age and pregnant women respectively [37].

Since anaemia during pregnancy has a deleterious consequences, WHO adopted reducing maternal mortality as one of the three health-related millennium development goals so that international community is committing within this framework to reduce maternal mortality by three quarter at the end of 2015 [38]. Anemia prevalence data remains an important indicator of public health since anemia is related to morbidity and mortality in the population groups usually considered to be the most vulnerable like pregnant women. At a global level, anemia prevalence is a useful indicator to assess the impact of widespread or highly effective interventions and to track the progress made towards the goal 
of reducing anemia during pregnancy [4]. Anemia prevalence study is also useful to monitor the progress of reproductive health [5]. Therefore, this study is aimed at determining prevalence of anemia and assessing associated risk factors among pregnant women attending antenatal care (ANC) at Adama Hospital Medical Collage in Eastshoa, Oromia, Ethiopia and which is very vital to take measure on prevention of anemia among pregnant mother and as well to prevent the complication associated with anemia.

\subsection{Significant of the Study}

The occurrence of anaemia among pregnant women is a significant health problem worldwide. Our country, Ethiopia is also affected with this problem as a part of the world. Since the consequence of anemia is gradual on an individual, the victims tolerate/ignore the problem for long time. Most of the victims did not know whether they are anaemic and the risk factors contributing to anaemia which associated with gravidity, low socioeconomic status, low educational level of mothers and family income in developing country like Ethiopia. On the other hand pregnant mothers did not give priority to health because most of them engaged in different works like preparing food for the whole family in addition to other works which means they are busy throughout the day. Therefore identification of the risk factors contributing to anaemia in pregnant mothers is vital to plan for anaemia prevention and control method in pregnant women.

This study is crucial in assessing the risk factors of anaemia among pregnant women in our country particularly in the study area, because in poor countries like ours where multifactorial causes of anaemia leads to maternal morbidity and mortality, identification of those factors is important to plan and to take appropriate measure to solve the problem from the grass root level.

Finding from the study may help for recognizing the severity of the problem, and to draw relevant recommendations which may be helpful in the effort to intervene the problem. For pregnant mothers the result of the study helps to reduce the complication that occurred as a result of anemia. The study helps the health worker to plan and implement during the ANC follow up. Furthermore, it may supply information for further research.

\section{Methods}

The main Objective is to determine the magnitude and factors associated with anemia during pregnancy among mothers attending antenatal care at Adama Hospital Medical College antenatal care clinic from November to December 2017. The specific objectives are to determine magnitude of anemia among pregnant mothers attending antenatal care at
Adama Hospital Medical College and to identify factors affecting anemia among pregnant mothers attending antenatal care at Adama Hospital Medical College.

Institution based cross sectional study design was used in Adama Hospital Medical College from November to December 2017. The study participants were selected using systematic sampling technique from their sequence of antenatal care visit in the period of study, and associated risk factors data were collected using structured questionnaire by trained antenatal care service providers. Level of hemoglobin was determined. Descriptive and analytical statistics were computed using SPSS version 20. Odds Ratios, P-values and 95\% CIs - the analytical statistics from bivariate and multi variate logstic regression were used to identify predictor variables associated with the dependent variable - anaemia.

\section{Result}

\subsection{Socio-Demographic Characteristics}

Out of a total sample size 329 (97.05\%) pregnant women were included and there was a nonresponsive rate of $2.94 \%$. The mean ages of the mothers is $26.5 \pm$ (4.01). Majority of the mother $310(94.2 \%)$ were married, $12(3.64 \%)$ were single and $7(2.12 \%)$ were divorced. Three hundred eighteen $96.6 \%$ of the women came from urban and $11(3.4 \%)$ came from rural. Out of 329 woman, one hundred and nine $32.8 \%$ were tertiary level or completed grade 10 and above $26.4 \%$ were grade $9-10$ and $23.3 \%$ were grade $5-8$ and $9.5 \%$ were illiterate.

About $178(54.3 \%)$ of the mothers were in their third trimester, $122(37.1 \%)$ were in the second trimester, and the remaining $29(8.8 \%)$ were in the first trimester. (Table 1)

\subsection{Prevalence of Anemia}

From the total 329 respondents $49(14.9 \%)$ were anemic, $10(20.4 \%)$ were moderately anemic, and 39 (79.5\%) were mildly anaemia according to WHO classification for degree of anemia. The mean hemoglobin level was $11.9( \pm 1.4) \mathrm{g} / \mathrm{dl}$. Most of them $(57.14 \%)$ were multiparous $(\geq 2)$ and multi gravidous $(\geq 3)$. The prevalence of anaemia in pregnant women who took iron tablets and who did not take iron tablets during pregnancy was $18(36.73 \%)$ and $31(63.28 \%)$ respectively. Prevalence of anaemia in first trimester, second trimester, and third trimester was $6.12 \%, 28.57 \%$ and $65.31 \%$ respectively. The trend of anaemia showed that as gestational age increase, the occurrence of anaemia also increases. The prevalence of anemia with MUAC, pregnant mothers whose MUAC less than $<21 \mathrm{~cm}, 21 \mathrm{~cm}$ to $23 \mathrm{~cm}$ and greater than $23 \mathrm{~cm}$ was $36.3 \%(55.10 \%)$ and $4 \%$ respectively (table 2 ). 
Mothers Attending Anc Clinic at Adama Hospital Medical Collage, Adama, Ethiopia, 2017

Table 1. Sociodemographic characteristics of pregnant women at Adama Hospital medical College, Oromia Region, Ethiopia, November to December 2017.

\begin{tabular}{|c|c|c|c|}
\hline Characteristics & & Total number & Percent \\
\hline \multirow{5}{*}{ Age } & $<=18$ & 5 & 1.5 \\
\hline & $19-25$ & 146 & 44.78 \\
\hline & $26-30$ & 135 & 41.41 \\
\hline & $31-36$ & 33 & 10.12 \\
\hline & $>37$ & 8 & 2.45 \\
\hline \multirow{3}{*}{ Marital status } & Married & 310 & $94.2 \%$ \\
\hline & Single & 12 & $3.7 \%$ \\
\hline & Divorced & 7 & $2.1 \%$ \\
\hline \multirow{3}{*}{ Religion } & Orthodox & 187 & $56.4 \%$ \\
\hline & Muslim & 83 & $25.5 \%$ \\
\hline & Protestant & 59 & $18.1 \%$ \\
\hline \multirow{6}{*}{ Occupation } & Housewife & 167 & $50.8 \%$ \\
\hline & Employee & 75 & $22.8 \%$ \\
\hline & Merchant & 35 & $10.6 \%$ \\
\hline & Daily labror & 8 & $2.5 \%$ \\
\hline & Farmer & 4 & $1.2 \%$ \\
\hline & Others & 41 & $12.6 \%$ \\
\hline \multirow{2}{*}{ Residence of the mother } & Urban & 318 & $96.6 \%$ \\
\hline & Rural & 11 & $3.4 \%$ \\
\hline \multirow{5}{*}{ Educational status } & Illiterate & 31 & $9.5 \%$ \\
\hline & First cycle (1-4) & 24 & $7.4 \%$ \\
\hline & Second cycle (5-8) & 76 & $23.3 \%$ \\
\hline & High school (9-10) & 86 & 26.4 \\
\hline & Tertiary above grade 10 & 109 & 33.4 \\
\hline \multirow{3}{*}{ Monthly income } & Less than 1000birr & 74 & $22.5 \%$ \\
\hline & 1000 to 2000 birr & 97 & $29.5 \%$ \\
\hline & Greater than 3000 birr & 158 & $48 \%$ \\
\hline \multirow{2}{*}{ Knowledge about anemia } & Yes & 38 & $11.6 \%$ \\
\hline & No & 291 & $88.4 \%$ \\
\hline
\end{tabular}

Table 2. Distribution of anaemia in pregnant women attending antenatal care with different variables at Adama Hospital Medical College 2017.

\begin{tabular}{|c|c|c|c|c|}
\hline Variables & & Anemic $\mathrm{N}=49 \%$ & Non anemic $\mathrm{N}=\mathbf{2 8 0} \%$ & Total number \\
\hline \multirow{2}{*}{ Parity } & Nully Para & $21(42.86 \%)$ & $125(44.64 \%)$ & 146 \\
\hline & Multipara & $28(57.14 \%)$ & $155(55.35 \%)$ & 183 \\
\hline \multirow{2}{*}{ Iron supplementation } & Yes & $18(36.73 \%)$ & $209(74.6 \%)$ & 227 \\
\hline & No & $31(63.27 \%)$ & $71(25.38 \%)$ & 102 \\
\hline \multirow{2}{*}{$\begin{array}{l}\text { Bleeding during index } \\
\text { pregnancy }(\mathrm{APH})\end{array}$} & Yes & $2(4.08 \%)$ & $10(2.86 \%)$ & 10 \\
\hline & No & $47(95.92 \%)$ & $272(97.14 \%)$ & 319 \\
\hline \multirow{3}{*}{ Trimester } & First & $3(6.12 \%)$ & $26(9.29 \%)$ & 29 \\
\hline & Second & $14(28.57 \%)$ & $108(38.57 \%)$ & 122 \\
\hline & Third & $32(65.31 \%)$ & $146(52.14 \%)$ & 178 \\
\hline \multirow{2}{*}{ Abortion } & Yes & $16(32.65 \%)$ & $71(25.38 \%)$ & 87 \\
\hline & No & $33(67.35 \%)$ & $209(74.64 \%)$ & 242 \\
\hline \multirow{2}{*}{ Birth interval } & $<=2$ year & $3(11.1 \%)$ & $30(19.23 \%)$ & 33 \\
\hline & $>2$ year & $24(88.29 \%)$ & $126(80.77 \%)$ & 150 \\
\hline \multirow{3}{*}{ MUAC } & $<21 \mathrm{~cm}$ & $18(36.73 \%)$ & 0 & 18 \\
\hline & $21-23 \mathrm{~cm}$ & $27(55.10 \%)$ & $43(15.38 \%)$ & 70 \\
\hline & $>23 \mathrm{~cm}$ & $4(8.16 \%)$ & $237(84.64 \%)$ & 241 \\
\hline \multirow{2}{*}{ Contraception } & Yes & $18(36.73 \%)$ & $158(56.43 \%)$ & 176 \\
\hline & No & $31(63.27 \%)$ & $122(43.57 \%)$ & 153 \\
\hline \multirow{2}{*}{ Presence of pica } & Yes & 42 & 26 & 68 \\
\hline & No & 7 & 254 & 261 \\
\hline \multirow{2}{*}{ Food aversion } & Yes & 38 & 123 & 161 \\
\hline & No & 11 & 157 & 168 \\
\hline
\end{tabular}




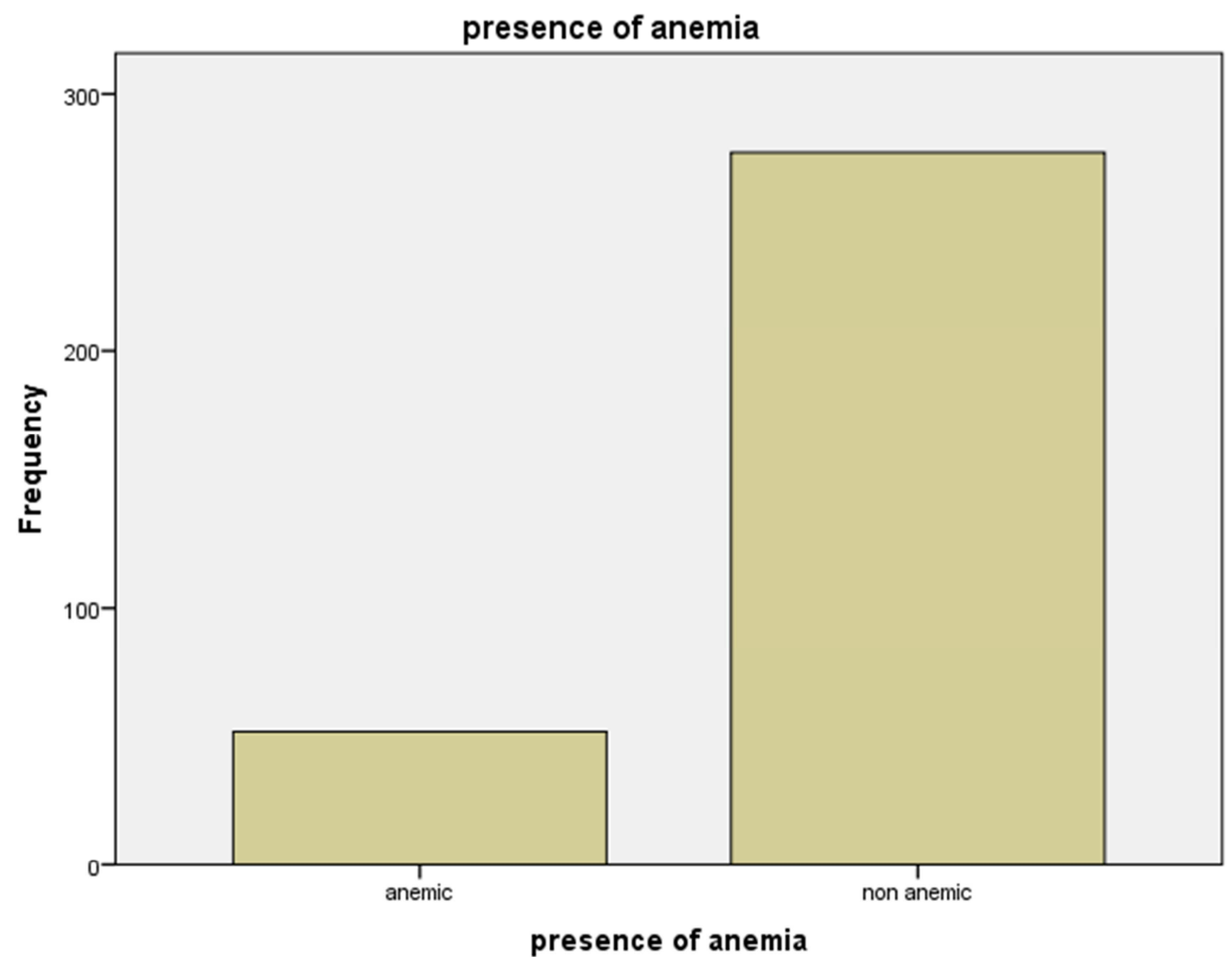

Figure 1. Prevalence of anaemia among pregnant mothers attending ANC clinic at Adama Hospital Medical College in 2017.

\subsection{Factors Associated with Anemia}

Bivariate analysis regression showed that history of pica, history of food aversion and iron supplementation were significantly associated with occurrence of anaemia during pregnancy as shown on (table 3)

Multivariate logistic regression analysis revealed that pica during pregnancy and iron supplementation was significantly associated with anemia in the study population (table 3 ).
Pregnant women who had pica during pregnancy had 33.6(13.92-81.48) times more likely to be anemic compared with those had no history of pica. Pregnant women who didn't take iron supplementation during their pregnancy were $0.196(0.085-0.445)$ times more likely to be affected by anemia when they compared with those who took iron supplementation.

Table 3. Multivariate logistic regression analysis of anaemia by determinants of anaemia in pregnant women attending antenatal follow up at Adama Hospital Medical College, 2017.

\begin{tabular}{lll}
\hline Predictors & Unadjusted OR (95\% CI) (Crude OR) & Adjusted OR(95 \% CI) \\
\hline History of pica & $0.025(0.011-0.055)$ & $33.67(13.92-81.48)$ \\
History of food aversion & $0.294(0.153-0.056)$ & $1.32(.53-3.20)$ \\
Iron supplementation & $6.023(3.20-11.32)$ & $0.196(.085-0.445)$ \\
\hline
\end{tabular}

\section{Discussion}

Only $(14.9 \%)$ of the pregnant women studied were anemic. This figure is much lower than the prevalence of anemia in pregnant women of some other developing countries such as India and Pakistan $[39,40]$. This may be due to the inclusion of more rural villages in the studies from Pakistan and India, which were not included in this study. This finding is lower than the national prevalence of anemia in pregnant women, which is $22 \%$ [29], and also much lowers than the prevalence noted from the 2011 Ethiopian Demographic Health Survey (EDHS) report, which found that $30.4 \%$ of Ethiopians were anemic [34]. This is discrepancy could be due to the exclusion of geographic zones and the time gap between the current study and the 2011 EDHS but the finding is almost in consistency with the cross sectional studies done in Jima town and Tikur Anbessa Specialized Hospital 16.6\%, and $21.3 \%[18,19]$.

However, the prevalence of severe anemia was none in this study than the $2 \%$ to $7 \%$ reported for developing countries [41]. This might be due to routine iron supplementation started from the early pregnancy ANC follow up. Nearly half of the women had borderline anemia, with hemoglobin concentrations more than $10 \mathrm{~g} / \mathrm{dL}$ but less than $11 \mathrm{~g} / \mathrm{dL}$. These are interesting and inspire findings for policy makers, 
because the attempt required to reduce the prevalence of anemia in nearly half of pregnant urban women should not be as great as that needed to produce normal hemoglobin levels in women with more severe anemia.

Two variables with significant association with anemia were pica during pregnancy and iron supplementation. The risk of developing anemia increased in pregnant women who had pica during pregnancy when compared with those who didn't have pica. The risk of developing anemia was higher in pregnant mother who has history of pica but the studies done in Pakistan, India or Ethiopia didn't reveal it [42, 43].

The risk of developing anemia increased in pregnant women who did not receive iron supplementation during pregnancy when compared with those who received iron supplementation. This finding is consistent with the findings from studies in Vietnam and Gode town, which indicated that lack of iron supplementation, is among the most significant risk factors for developing anemia during pregnancy [39, 44].

Anemia prevalence was higher in the third trimesters than in the second and first trimester in this study. Prevalence of anemia is increased as gestational age increases. This might be due to increase in hemo-dilution as a result of increase in estrogens level towards the end of gestational age [42]. Increase in anemia prevalence in the third trimester ascertained in this study was similar with what was reported in other study done in Shalla woreda of Ethiopia [43, 44].

Other independent variables which are not significant factors in this study but found to be significant by other studies reviewed include age of the mother, religion, number of deliveries, number of children, family size, educational Status of the mother, and occupation of the mother [34].

\subsection{Strength of the Study}

This study was using primary data which was collected by the investigators and full participation of the respondents. This primary data collected by investigators may increase the accuracy of it. A time line is also other strength of this study. This study can be baseline main source of data for further study on this title.

\subsection{Limitation of the Study}

I was unable to account for other known factors associated with anemia, genetic disorders, or other nutritional deficiencies such as folate, vitamin $\mathrm{B}_{12}$, and vitamin $\mathrm{A}$ deficiency. Although helminthes infection contributes to the prevalence of anemia [30], it may not be an important factor in this study since there was improvement in hygiene and shoe wearing practice in residence of the town. Due to constraint of time and resource, stool concentration technique and parasite density were not done so we could not assess the impact of parasite load on the severity of anemia.

\section{Conclusion}

The prevalence of anemia among pregnant women in this study was almost similar when compared with women in other areas of Ethiopia. Pica during pregnancy and iron supplementation were found to be significantly associated with anemia. Education and creating awareness about maternal nutrition during pregnancy and iron supplementation during pregnancy are recommended to reduce anemia. Further research on risk factors of anemia, which include rural residents, should be conducted to strengthen and broaden these findings.

\section{Recommendations}

Health education and creating awareness on maternal nutrition during pregnancy should be emphasized in association with ANC follow up. Iron supplementation should be strictly applied for all pregnant mothers.

\author{
Abbreviation and Acronyms \\ $\mathrm{Hb}$-haemoglobin \\ WHO-world health organization \\ FMOH -federal ministry of health \\ AHMC-Adama hospital medical collage \\ ANC - Antenatal care \\ APH - Antepartum haemorrhage \\ IDA - Iron Deficiency Anemia \\ ID - Iron Deficiency \\ MCH - Maternal and child health \\ MDG - Millennium development goal \\ PMTCT - Prevention of mother to child transmission of \\ HIV \\ PPH - Postpartum hemorrhage \\ WCBA- Women of child bearing age \\ PW-pregnant women \\ MUAC-mid upper arm circumference
}

\section{Competing Interests}

The Authors declare that they have no competing interests.

\section{Authors Contributions}

The Authors are Bizuneh Ayano ${ }^{1}$ and Dr. Befekadu Amentie $^{2}$ both of them developed research proposal, searching for funding, data collection, controlling data collectors, supervising, compiling, and organizing, finally research reporting and defense. Bizuneh Ayano has also prepared research manuscript.

\section{Acknowledgements}

First of all I would like to extend my great thanks to, Girma Mulisa for his guidance and constructive comments through the development of this Research from proposal to final thesis writing and those contributed their constructive suggestion.

I would like to express my special appreciation to Adama Hospital Medical College ANC midwifes workers and all of 
the study participants who have shown their willingness to participate in this study.

Lastly but not least I would like to extend thanks to all of my family and friends for their support in my academic life.

\section{Appendix}

\section{English Version Participant Information Sheet and Consent Form}

Consent form for the study entitled to assess the magnitude and factors associated with anaemia during pregnancy among mothers attending antenatal care at Adama Hospital Medical College antenatal care clinic; in Ethiopia.

\section{Consent form}

\section{Information to Study participants}

Title of the study: Assessing the magnitude and factors associated with anaemia during pregnancy among mothers attending antenatal care at Adama Hospital Medical College antenatal care clinic; in Ethiopia.

\section{Introduction}

Greeting--

My name is and I am working after graduated my master's degree in Public health, at University of Wolaita Sodo; Now I am Lecturer at Addis Ababa University Selale campus. I am planning to conduct study on Assessing the magnitude and factors associated with anaemia during pregnancy among mothers attending antenatal care at Adama Hospital Medical College antenatal care clinic; in Ethiopia.

Whatever information you would provide will be kept confidential. We will not record your name on the questionnaire. Your name will not be identified in any output of this study. You have full right to withdraw from this study at any time without a need to mention the reason why you wanted to withdraw. We value your input to make this study a successful one.

Purpose of the study

The main purpose of this study is to assess the magnitude and factors associated with anaemia during pregnancy among mothers attending antenatal care at Adama Hospital Medical College antenatal care clinic; in Ethiopia.

The information that you will provide us will help us to improve anemia prevalence and prevention service program in the study area in particular and in Ethiopia in general.

\section{Procedures}

If you agree to participate in this study, we will interview you about anaemia prevalence and prevention.

Potential risks and discomfort of being in the study

By participating in this research project, you may have some discomfort. There are no or minimal anticipated risk but taking time about 30 minute for interview.

Benefits of being in the study

There may not be direct benefits to you for giving us information for the study. In the future ifanaemia prevention and control service coverage is increased you have in directly benefit due to healthy condition of you and your community.

\section{Confidentiality and Privacy Protections:}

The records of this study will be stored securely and kept confidential. All publications will exclude any information that will make it possible to identify you as a subject.

Contacts and Questions:

If you have any questions about the study please ask me now. If you have questions later, want additional information, or wish to withdraw call the researcher conducting the study. If you have questions about the research please contact Bizuneh Ayano and Dr. Befekadu Amentie who are principal investigators of this study in the University of Addis Ababa at $+251(0) 911381859$ and +251921207417 . You are making a decision about allowing participating in this study. Your signature below indicates that you have read or has been read to you the information provided above and has decided to participate in the study. If you later decide that you wish to withdraw to participate in the study, simply tell me. You may discontinue your participation at any time.

Name of study participant:

Signature: Date:

Name of data collector

Signature Date

\section{References}

[1] World Health Organization/United Nations University/UNICEF: Iron Deficiency Anemia, Assessment, Prevention and Control: A Guide for Programme Managers. Geneva: WHO; 2001.

[2] WHO: Reducing Risks, Promoting Healthy Life, The World health report. Geneva, Switzerland; 2001.

[3] World Health Organization. WHO/NUT/MCM/92.2. WHO; Geneva: 1992. The prevalence of anemia in women: A tabulation of available information.

[4] WHO. The World Health Report 2002: Reducing risks, promoting healthy life. Geneva, World Health Organization, 2002.

[5] Benoist B, McLean E, Egli I, Cogswell M, World Health Organization, Centers for Disease Control and Prevention (Eds): Worldwide Prevalence of Anemia 1993-2005. Geneva: World Health Organization; 2008.

[6] AAdish, SA Esrey, TW Gyorkos, et. al. Risk factors for iron deficiency anaemia in preschool children in northern Ethiopia. Public Health Nutrition 1998; 2(3): 243-252.

[7] Y. Balarajan, U. Ramakrishnan, E. Özaltin, A. H. Shankar, and S. V. Subramanian, "Anaemia in low-income and middleincome countries," The Lancet, vol. 378, no. 9809, pp. 2123 2135, 2011. View at Publisher View at Google Scholar View at Scopus.

[8] WHO, UNICEF, UNFPA, and World Bank, Maternal Mortality in 2005: Estimates Developed by WHO, UNICEF, UNFPA and World Bank, WHO, Geneva, Switzerland, 2007.

[9] WHO and UNICEF, Focusing on Anaemia: Towards an Integrated Approach for Effective Anaemia Control, WHO, Geneva, Switzerland, 2004. 
[10] E. McLean, M. Cogswell, I. Egli, D. Wojdyla, and B. De Benoist, "Worldwide prevalence of anaemia, WHO Vitamin and Mineral Nutrition Information System, 1993-2005," Public Health Nutrition, vol. 12, no. 4, pp. 444-454, 2009. View at ublisher View at Google Scholar View at Scopus.

[11] Ethiopia, Demographic and Health Survey, Central Statistics Agency, Addis Ababa, Ethiopia, 2011.

[12] Mulugeta Melku, Zelalem Addis, Meseret Alem and BamlakuEnawgaw Research ArticlePrevalence and Predictors of Maternal Anemia during Pregnancy in Gondar, Northwest Ethiopia: An Institutional Based Cross-Sectional Study Volume 2014 (2014), Article ID 108593, 9 pages http://dx.doi.org/10.1155/2014/108593

[13] Ethiopia Central Statistical Agency and ICF International: 2011 Ethiopia Demographic and Health Survey: Key Findings. Calverton, Maryland, USA: CSA and ICF International; 2012.

[14] Walter T: Effect of iron-deficiency anemia on cognitive skills and neuromaturation in infancy and childhood. Food Nutr Bull 2003, 24:S104-S110. PubMed Abstract.

[15] Juarez-Cedillo T, Basurto-Acevedo L, Vega-Garcia S, Manuel-Apolinar L, Cruz-Tesoro E, Rodriguez-Perez JM, Garcia-Hernandez N, Perez-Hernández N, Fragoso JM: Prevalence of anemia and its impact on the state of frailty in elderly people living in the community: SADEM study. Ann Hematol 2014. doi:10.1007/s00277-014-2155-4.

[16] Chen MH, Su TP, Chen YS, Hsu JW, Huang KL, Chang WH, Chen TJ, Bai YM: Association between psychiatric disorders and iron deficiency anemia among children and adolescents: A nationwide population-based study. BMC Psychiatry 2013, 13:161. PubMed Abstract | BioMed Central Full Text PubMed Central Full Text.

[17] Jufar AH, Zewde T: Prevalence of anemia among pregnant women attending antenatal care at tikuranbessa specialized hospital, Addis Ababa Ethiopia. J HematolThromb Dis 2014. 2 doi:10.4172/2329-8790.1000125

[18] Filagot Kefiyalew, Endalew Zemene, Yaregal Asres and Lealem Gedefaw BMC Research Notes 2014, 7:771 doi: 10.1186/1756-0500-7-771Rrisk factors for anemia among pregnant women attending antenatal clinic at jimma university hospital, southwest ethiopia. belachew t, legesse y. ethiop med j. 2006 jul;44(3):211-20.

[19] Desalegn S: Prevalence of anemia in pregnancy in jimma town, southwestern Ethiopia. Ethiop Med J 1993, 31:251-258. PubMed Abstract.

[20] F. W. Lone, R. N. Qureshi, and F. Emanuel, "Maternal anaemia and its impact on perinatal outcome," Tropical Medicine and International Health, vol. 9, no. 4, pp. 486-490, 2004. View at Publisher View at Google Scholar View at Scopus.

[21] T. Kousar, Y. Memon, S. Sheikh, S. Memon, and R. Sehto, "Risk factors and causes of death in Neonates," Rawal Medical Journal, vol. 35, no. 2, pp. 205-208, 2010. View at Google Scholar View at Scopus.

[22] B. J. Brabin, M. Hakimi, and D. Pelletier, "An analysis of anemia and pregnancy-related maternal mortality," Journal of Nutrition, vol. 131, no. 2, pp. 604S-615S, 2001. View at Google Scholar View at Scopus.
[23] T. Marchant, J. A. Schellenberg, R. Nathan et al., "Anaemia in pregnancy and infant mortality in Tanzania," Tropical Medicine and International Health, vol. 9, no. 2, pp. 262-266, 2004. View at Publisher View at Google Scholar.

[24] View at Scopus Sight and Life, "Nutritional Anemia," SIGHT AND LIFE Press, 2007,

http://www.sightandlife.org/fileadmin/data/Books/Nutritional_ anemia_book.pdf.

[25] S. Ouédraogo, G. K. Koura, K. Accrombessi, F. BodeauLivinec, A. Massougbodji, and M. Cot, "Maternal anemia at first antenatal visit: prevalence and risk factors in a malariaendemic area in Benin," The American Journal of Tropical Medicine and Hygiene, vol. 87, no. 3, pp. 418-424, 2012. View at Google Scholar.

[26] K. Tolentino and J. F. Friedman, "An update on anemia in less developed countries," The American Journal of Tropical Medicine and Hygiene, vol. 77, no. 1, pp. 44-51, 2007. View at Google Scholar View at Scopus.

[27] Determinants of anaemia in pregnantWomen with emphasis on intestinal Helminthic infection at bushulo health Center southern ethiopiabamlakutadegetsehayu Feburary, 2009 addisababa, Ethiopia.

[28] Survey of causes of death (rural), India: annual report 1994. New Dehli: Office of the Registra-General, India, 1994. K. E. Agho et. al.

[29] Factors Associated with Haemoglobin Concentration among Timor-Leste Children Aged 6-59 Months. J. Health Popul. Nutrition 2008; 26(2):200-209.

[30] Lindsay H. Allen. Biological mechanisms that might underlie iron's effects on fetal growth and preterm birth. Journal of Nutrition2001; 131:581S-9S.

[31] Steer PJ. Maternal haemoglobin concentration and birth weight. Am. J. Clin. Nutr. 2000; 71:1285S-1287S.

[32] Micronutrient initiative. Ethiopian Country Profile (document on the enternet). The institute 2006; [cited 2009 Dec 20]. Avialable from: http://micronutrients

[33] Anemia among pregnant women in Southeast Ethiopia: prevalence, severity and associated risk factorsmagnitude of anemia and associated risk factors among pregnant women attending antenatal care in shalla woreda, west arsi zone, oromia region, ethiopia.[ethiop j health sci. 2013 Office of the Registrar-General.

[34] World Health Organization (WHO). Nutrition. Geneva: WHO, www.who.int/nutrition/en: WHO 2007.

[35] Allen L, De Benoist B, Dary O, Hurrell R. Guidelines on food fortification with micronutrients. Geneva: WHO, 2006. Jane Crawley.

[36] Guyatt L., Snow W. (2001). The epidemiology and burden of Plasmodium falciparumrelatednemia among pregnant women in sub-Saharan Africa.Am.J. Trop.Med.Hyg. 64 (S1-2), 3644.

[37] G S. Toteja, P. Singh, B. S. Dhillon et al., "Prevalence of anemia among pregnant women and adolescent girls in 16 districts of India," Food and Nutrition Bulletin, vol. 27, no. 4, pp. 311-315, 2006. View at Google Scholar View at Scopus. 
[38] R Aikawa, N. C. Khan, S. Sasaki, and C. W. Binns, "Risk factors for iron-deficiency anaemia among pregnant women living in rural Vietnam," Public Health Nutrition, vol. 9, no. 4, pp. 443-448, 2006. View at Publisher View at Google Scholar.

[39] Esmat, R. Mohammad, S. Behnam et al., "Prevalence of iron deficiency anemia among iranian pregnant women; a systematic review and meta-analysis," Journal of Reproduction and Infertility, vol. 11, no. 1, pp. 17-24, 2010. View at Google Scholar.

[40] Pregnant Women, vol. 5, no. 3, pp. 216-223, 2012. View at Google Scholar.

[41] Z. Makhoul, D. Taren, B. Duncan et al., "Risk factors associated with anemia, iron deficiency and iron deficiency anemia in rural Nepali pregnant women," Southeast Asian Journal of Tropical Medicine and Public Health, vol. 43, no. 3, pp. $735-745,2012$. View at Google Scholar View at Scopus.
[42] M. Akhtar and I. Hassan, "Severe Anemia during late pregnancy," Case Reports in Obstetrics and Gynecology, vol. 2012, Article ID 485452, 3 pages, 2012. View at Publisher View at Google Scholar.

[43] Kefyalew Addis Alene1 and Abdulahi Mohamed Dohe Prevalence of Anemia and Associated Factors among Pregnant Women in an Urban Area of Eastern Ethiopia Volume 2014 (2014), Article ID 561567, 7 pages http://dx.doi.org/10.1155/2014/561567

[44] Susan T, Blackburn DO. Maternal, Fetal, \& Neonatal Physiology: A Clinical Niguse Obse, Andualem Mossie, and Teshome Gobena Magnitude of Anemia and Associated Risk Factors among Pregnant Women Attending Antenatal Care in Shalla Woreda, West Arsi Zone, Oromia Region, Ethiopia Ethiop J Health Sci. 2013 Jul; 23(2): 165-173. PMCID: PMC3742894. 